\title{
THE EFFECTS OF SYRINGE-TRANSMITTED JAUNDICE ON THE OUTCOME OF THE TREATMENT OF EARLY SYPHILIS
}

\author{
BY \\ R. R. WILLCOX
}

Physician in charge, Venereal Diseases Clinic, King Edward VII Memorial Hospital, Windsor. 'Assistant, Venereal Diseases Department St. Mary's Hospital, W.2. Late Adviser in Venereology to the War Office

During the world war 1939-45 the incidence. of post-arsphenamine hepatitis in many military and other venereal diseases clinics reached a very high percentage; in some centres up to fifty per cent. of cases. Observations by Bigger (1943) and MacCallum (1943), and large-scale experiments by Salaman and others (1944) and by Laird (1946), indicated that this disease was transmitted as a result of inadequate sterilization of syringes. Much has been written about the effect of jaundice on the patient, but little has so far been said about its result on the prognosis of the syphilitic infection under treatment.

\section{The Present Study}

This study is an analysis of case records of 556 male patients suffering from primary or secondary syphilis and observed at a hospital where this form of jaundice was particularly high. All patients began treatment on the four-course arsenic and bismuth schedule then in vogue. This consisted essentially of four courses of ten weekly injections to a total of $5.85 \mathrm{~g}$. of neoarsphenamine and $2.0 \mathrm{~g}$. of bismuth per course. There was usually a short initial period when the injections were given twice weekly, and a rest of one month was allowed between courses. The total length of treatment for an uncomplicated case was one year. Penicillin therapy was introduced during the time that many of the patients were under review, and a proportion of them received penicillin after one or more courses had been given in lieu of the remainder of the treatment. In these cases, commercial penicillin in aqueous solution, which may have contained from 10-40 per cent. of penicillin $\mathrm{K}$, was used in sixty three-hourly injections to a total of 2.4 million units.

Of the 556 patients, 278 developed jaundice and 278 did not. This exact splitting into two equal groups was coincidental and not arranged in any way. The average age of all patients was 29.28 years, and there was no significant difference of age in the two groups. Of the jaundiced patients, 199 received "long-term" treatment with bismuth and arsenic throughout, and 79 had their treatment curtailed by the substitution by penicillin. Of the nonjaundiced patients, 61 had the abbreviated treatment with penicillin, and 217 received arsenic and bismuth only. The stage of the syphilis of the patients in the two groups is shown in Table I.

Table I

STAGE OF SYPHILIS IN JAUNDICED AND NONJAUNDICED PATIENTS

\begin{tabular}{rr|r|r|r|r}
\hline \multicolumn{2}{|c|}{ Diagnostic Stage } & $\begin{array}{c}\text { Jaun- } \\
\text { dice }\end{array}$ & $\begin{array}{c}\text { No } \\
\text { jaun- } \\
\text { dice }\end{array}$ & Total & $\begin{array}{c}\text { Per } \\
\text { cent. }\end{array}$ \\
\hline $\begin{array}{r}\text { Sero-negative } \\
\text { primary .. }\end{array}$ &.. & 104 & 91 & 195 & $35 \cdot 1$ \\
$\begin{array}{r}\text { Sero-positive } \\
\text { primary .. }\end{array}$ &.. & 124 & 141 & 265 & $47 \cdot 7$ \\
$\begin{array}{rrrr}\text { Secondary } \\
\text { syphilis ... }\end{array}$ & .. & 50 & 46 & 96 & $17 \cdot 2$ \\
\hline Totals ... & 278 & 278 & 556 & $100 \cdot 0$ \\
\hline
\end{tabular}

These cases formed a large part of the investigations by Beattie and Marshall (1944), who indicated that the usual incubation period of the jaundice was 80 to 100 days. Of the 278 patients, 25 had had less than one course 
of treatment, 176 between one and two courses, 46 between two and three courses, 19 between three and four, and 12 more than four courses of treatment. Not all cases, however, commenced treatment at this clinic. The average amount and the duration of the treatment given is shown in Table II.

TABLe II

AVERAGE AMOUNT AND DURATION OF TREATMENT

\begin{tabular}{c|c|c|c|c|c|c}
\hline $\begin{array}{c}\text { Type } \\
\text { of } \\
\text { treat- } \\
\text { ment }\end{array}$ & $\begin{array}{c}\text { Average } \\
\text { duration of } \\
\text { treatment in } \\
\text { months }\end{array}$ & $\begin{array}{c}\text { Average } \\
\text { amount of } \\
\text { arsenic in } \\
\text { g. }\end{array}$ & \multicolumn{2}{|c|}{$\begin{array}{c}\text { Average } \\
\text { amount of } \\
\text { bismuth in } \\
\text { g. }\end{array}$} \\
\hline $\begin{array}{c}\text { Jaun- } \\
\text { dice }\end{array}$ & $\begin{array}{c}\text { No } \\
\text { jaun- } \\
\text { dice }\end{array}$ & $\begin{array}{c}\text { Jaun- } \\
\text { dice }\end{array}$ & $\begin{array}{c}\text { No } \\
\text { jaun- } \\
\text { dice }\end{array}$ & $\begin{array}{c}\text { Jaun- } \\
\text { dice }\end{array}$ & $\begin{array}{c}\text { No } \\
\text { jaun- } \\
\text { dice }\end{array}$ \\
\hline $\begin{array}{c}\text { Long- } \\
\text { term }\end{array}$ & 16.02 & 14.06 & 16.82 & 20.77 & 10.31 & 8.60 \\
$\begin{array}{c}\text { Short- } \\
\text { term }\end{array}$ & 11.55 & 7.46 & 8.75 & 10.11 & 6.60 & 4.30 \\
\hline
\end{tabular}

It will be observed that the patients who did not develop jaundice received on an average $3.95 \mathrm{~g}$. more of arsenic and $1.71 \mathrm{~g}$. less of bismuth on the long-term schedule, and $1.36 \mathrm{~g}$. more arsenic and $2.30 \mathrm{~g}$. less of bismuth with the curtailed treatment combined with penicillin, than did those patients who contracted the disease. Moreover, the jaundiced patients were actually under treatment for an average of two and four months longer than the non-jaundiced patients in the longer and shorter schedules respectifely.

Toxic Effects.-Seven patients of the jaundice group and six of the non-jaundice group developed bismuth stomatitis, while, of the complications other than jaundice due to arsenic (necessitating permanent stoppage of the drug), there were 12 in the former and 15 in the latter group. These included 21 cases of arsenical dermatitis, 4 of nitritoid crises, 1 of severe herpes zoster, and 1 of severe " ninth day erythema." There was thus no evidence that susceptibility to hepatitis means an increased susceptibility to the other complications of arsenic and bismuth. However, when these complications were grouped according to whether the patients had received the long- or the short-term treatment, it was found that the extra one and a half to two courses of arsenic given in the long-term schedule made little difference to the incidence
(19, or 4.57 per cent., occurring in the 416 patients treated on the long term schedule, and 8 , or 5.71 per cent., in the 140 patients by the shortened treatment with penicillin). The incidence of bismuth stomatitis, however, was substantially reduced on the latter treatment : there being only one case, or 0.71 per cent., as compared with 12 cases, or 2.88 per cent., with the former. The default rate, too, was lower with the shorter treatment, a point that has to be weighed in the balance in considering the slightly inferior results.

When jaundice developed it was the practice to admit the patient to hospital until he recovered, which process took an average of one month ; no more arsenic was administered until three months had elapsed following discharge, though bismuth therapy was not interrupted. There were no deaths in this series, but one case developed ascites, and subsequent liver punctures showed a marked cirrhosis of the liver. Details of this case have. been described by Dible and others (1943). Three years later this patient is still alive and apparently well. In spite of the resumption of the arsenic, only in six instances $(2 \cdot 1$ per cent.) was there a second attack of jaundice arising between two and fourteen months after the first.

Decline to Sero-negativity.-Tests of the blood sera were performed at the onset and before any subsequent courses of treatment. Of 361 cases of both groups which were seropositive at the commencement, 261 (72.3 per cent.) were sero-negative at the end of the first course, 85.6 per cent. at the end of the second, 92.25 per cent. at the end of the third, 95.02 at the end of the fourth, and a further 0.55 per cent. after the fourth course. 16 cases $(4.43$ per cent.) were resistant. There was no significant difference in the rate of decline to sero-negativity in the jaundiced and nonjaundiced cases, and the numbers ultimately sero-resistant were equal, being eight in each series (2.87 per cent.).

The Follow up.-At the conclusion of treatment it was customary to perform quarterly serological tests for one year followed by six-monthly tests for a further year during which time a cerebrospinal fluid examination was made. The European war ended and demobilization began while many of these patients were still under observation; even so, 71 per cent. were followed for six, $54 \cdot 5$ per cent. 
for nine, and 42.3 per cent. for twelve or more months after the conclusion of treatment. There was no appreciable difference in the success of the follow-up in the jaundiced and non-jaundiced group. The numbers of jaundice cases followed for six, nine, and twelve months were 197, 152, and 112 respectively, while for the non-jaundice cases the figures were 199, 151, and 123.

The Failures.-The accident of acquiring hepatitis made no difference to the possibility of sero-resistance, nor to the incidence of relapse. There were 12 relapses (4.32 per cent.) in the non-jaundice group, and only 9 (3.24 per cent.) in those who had had jaundice. Of the 21 relapses, there were 3 with dark-field positive lesions, 2 with a positive serological reaction at five and seven months respectively, and 1 with a negative at fifteen months. Two suffered neurological relapse, $i$ of asymptomatic neurosyphilis at ten, and 1 of symptomatic neurosyphilis at fifteen months. The remaining 16 were serological relapses, occurring in 3 at three months, in 2 at six, in 5 at nine, and in 6 at the twelfth month of surveillance. These figures must be correlated with the fact that only $42 \cdot 3$ per cent. were actually followed for the year.

There were thus 37 failures; 17 (8 resistant and 9 relapses) in the jaundiced group, and 20 (8 resistant and 12 relapses) in the nonjaundiced group. There was no evidence that these patients received less treatment than the average of the groups from which they arose. Only in 1 had there been any severe arsenical complication (dermatitis), although 4 developed bismuth stomatitis. Only 4 had intervals of default exceeding three months, which was comparable in proportion to the series as a whole. Fourteen of the relapses occurred in the 416 patients treated on the long-term schedule (3.37 per cent.), while there was a slightly greater ratio, 7 in 140 cases, in those treated on the shorter schedule with penicillin ( 5 per cent.).

One of the failures was particularly disturbing. The case was that of a man aged 36 who was treated in February, 1944, for secondary syphilis. He had no jaundice or other complication before the four courses had been completed in March, 1945. His blood had become negative after the first course and remained so subsequently, and was still negative one month after completion, at which stage he was demobilized. It was learnt fifteen months later that he was in a civilian hospital with Erb's spastic paraplegia and strongly positive serological and cerebrospinal fluid findings.

Of the 37 failures, 3 arose from the 195 sero-negative primary cases (1.54 per cent.), 16 from the 265 sero-positive primary cases (6.04 per cent.), and 18 from the 96 secondary cases (18.74 per cent.). The proportion of failures, therefore; increased according to the duration of the syphilitic infection before treatment.

\section{Summary and Conclusions}

Two hundred and seventy-eight cases of early syphilis developing sýringe-transmitted hepatitis are contrasted with 278 patients who received similar treatment in the same clinic but did not develop jaundice. It was coincidental that the two groups are of equal number.

The jaundice cases received less arsenic but more bismuth, and were under treatment for a longer time than the non-jaundice cases.

There was no difference in the incidence of other toxic manifestations in the two groups, although the incidence of bismuth stomatitis was lower; while the complications due to arsenic were not reduced when penicillin was combined with a smaller amount of arsenic and bismuth.

Of the cases followed, the numbers showing sero-resistance were equal in the two groups, though in this series there was actually a slight increase in the numbers of relapses in the non-jaundiced as compared with the jaundiced cases.

It would, therefore, appear that whatever the results on the life span of the unfortunately large number of patients who developed hepatitis while under anti-syphilitic treatment, at any rate the outcome of the treatment given for early syphilis is not prejudiced.

\section{REFERENCES}

Beattie, J., and Marshall, J. (1944). Brit. med. J., $1,547$.

Bigger, J. W. (1943). Lancet, 1, 457.

Dible, J. H., McMichael, J., and Sherlock, S. P. V. (1943). Ibid., 2, 402.

Laird, S. M. (1946). Brit. J. vener. Dis., 22, 29. MacCallum, F. O. (1943). Ibid., 19, 63.

Salaman, M. H., King, A. J., Williams, D. I., and Nicol, C. S. (1944). Lancet, $2,7$. 